\title{
Internet Addiction and Psychological Well-being among Youth of Kashmir
}

\author{
Aasimeh Rehman ${ }^{1} *$, Humera Shafi ${ }^{2}$, Touseef Rizvi ${ }^{2}$
}

\section{ABSTRACT}

The present study was conducted with the aim to examine the relationship between internet addiction and psychological well-being among youth of Kashmir and to find out the difference in both addiction and psychological well-being among youth of Kashmir with respect to gender and residential status. 100 students studying in various colleges of two districts of Kashmir (Srinagar and Ganderbal) completed the Young's Internet addiction test (Young, 1998) and Ryff's Psychological well-being scale (Ryff, 1995). Results of the study revealed a significant negative correlation between internet addiction and psychological well-being among youth of Kashmir. Further it was found that there is significant difference in internet addiction among youth of Kashmir with respect to their gender, males were found to be high on internet addiction than their counter parts and no significant difference was found in internet addiction with respect to their residential status. Results also revealed insignificant difference in psychological well-being among male and female youth and regarding their residential status significant difference was found in psychological well-being, urban youth were found to be high on the levels of psychological well being as compared to rural youth. The study will be helpful in highlighting the effect of internet addiction among youth which is becoming a menace day by day for society.

Keywords: Internet addiction, Psychological wellbeing, Youth.

The Internet swiftly entered the life of the humankind in the 20th century. It took us less than ten years to face the fact of its spreading all over the world, including the developing countries. It has not only become source of information in the world, but also the most rapid means of communication. People from different countries have got an opportunity to communicate with each other in quite a short time. Internet is a technological tool which makes our life easier and has become an indispensable part of it while it's number of user population increases faster each day (Isman and Dabaj, 2004; Yapici, and Akbayin, 2012). The concept of internet addiction was

\footnotetext{
${ }^{1}$ Ph.D. Research Scholar, Dept of psychology, University of Kashmir, Srinagar

${ }^{2}$ Sr. Asst Professor, Dept of psychology, University of Kashmir, Srinagar

*Responding Author

(c) 2016 I A Rehman, H Shafi, T Rizvi; licensee IJIP. This is an Open Access Research distributed under the terms of the Creative Commons Attribution License (http://creativecommons.org/licenses/by/2.0), which permits unrestricted use, distribution, and reproduction in any Medium, provided the original work is properly cited.
} 


\section{Internet Addiction and Psychological Well-being among Youth of Kashmir}

first introduced in a pioneer study by Young (1996). Internet gaming disorder (also commonly referred to as Internet use disorder, Internet addiction or gaming addiction) is a pattern of excessive and prolonged internet gaming that results in cluster of cognitive and behavioral symptoms including progressive loss of control over gambling, tolerance, and withdrawal symptoms analogous to the symptoms of substance use disorder. As with substance related disorder, individuals with internet addiction continue to sit at a computer and engage in gambling activities despite neglect of other activities. They typically devote 8-10 hours or more per day to this activity and at least 30 hours per week. They often go for long periods without food or sleep (DSM 5). Internet causes an overall negative effect on daily lives and a break in the individual's psychological wellbeing. Studies about the reasons for internet addiction showed that characteristics like shyness, depressive signs and low self-esteem (Aydin and Sari, 2011) are attributed with inclination towards internet addiction (Yang and Tung, 2007). As addiction to internet increases the dimensions in wellbeing decreases (Waldo, 2014). Well-being is a positive and sustainable condition that allows individuals, groups or nations to thrive and flourish Psychological well-being is about lives going well. It is the combination of feeling good and functioning effectively (Huppert, Baylis \& Keverne., 2005). Students with higher levels of Internet addiction are more likely to be low in psychological well-being (Cardaks, 2013). Students who are addicted to internet usage have psychiatric symptoms such as Somatization, Obsessive Compulsive, interpersonal sensitivity, depression, anxiety, hostility, phobic anxiety, paranoid ideation and psychoticism more than students who are non addicted internet usage (Koc, 2011). Depression, anxiety, and stress were predicted positively in internet addiction (Akin and Iskender, 2011).

\section{OBJECTIVES}

1. To study the relationship between internet addiction and psychological wellbeing among youth of Kashmir.

2. To study the difference in both internet addiction and psychological wellbeing among youth of Kashmir with respect to their gender and residential status.

\section{Hypothesis:}

$\mathrm{H}_{01}$ There will be no significant correlation between internet addiction and psychological wellbeing among youth of Kashmir.

$\mathrm{H}_{02}$ There is no significant difference in internet addiction among youth of Kashmir as far as their gender is concerned.

$\mathrm{H}_{03}$ There is no significant difference in internet addiction among youth of Kashmir as far as their residential status is concerned.

$\mathrm{H}_{04}$ There is no significant difference in psychological wellbeing among youth of Kashmir as far as their gender is concerned.

$\mathrm{H}_{05}$ There is no significant difference in psychological wellbeing among youth of Kashmir as far as their residential status is concerned. 


\section{METHODOLOGY}

\section{Sample:}

The present study consists of a sample of 100 participants taken from two districts (Srinagar \& Ganderbal) of Kashmir province. An equal ratio of male and female participants, that is 50 males and 50 females were taken.

\section{Description of tools:}

Young's Internet Addiction Test (Young, 1998). This was adapted to evaluate respondent's level of internet addiction. It consists of 20 questions wherein each item is scored using a fivepoint Likert scale. It covers the degree to which internet use affect daily routine, social life, productivity, sleeping pattern, and feeling. The instrument has exhibited good psychometric properties in previous researches. The reliability for this questionnaire is 0.899 in Cronbach's alpha the higher the score the greater the level of internet addiction.

Ryff's Psychological wellbeing scale (Ryff, 1995): This scale is adapted to measure the psychological well beings of respondents. It consists of 18 items which measures six dimensions of psychological wellbeing (Autonomy, Environmental mastery, Personal growth, Positive Relations, Purpose in life, Self-acceptance) and each item is scored using a seven-point scale.

\section{Statistical analysis:}

Keeping in view the nature of research problem and to meet the objectives of the study the data collected was analyzed by using Statistical package for social sciences (SPSS v-20). Statistical techniques used for analyzing data were: Pearson's correlation coefficient and t-test. The statistical significance value was set at $\mathrm{p} \leq 0.05$.

\section{RESULTS}

Table 1 Showing correlation between internet addiction and psychological well being among youth of Kashmir.

\begin{tabular}{lrcrc}
\hline Variable & $\mathbf{N}$ & Mean & SD & $\mathbf{r}=$ \\
Internet addiction & & 45.31 & 14.17 & $-.218^{*}(\mathrm{P}=.030)$ \\
& 100 & & &
\end{tabular}

*Significant at 0.05 level of significance.

Table 1 reveals the correlation coefficient of internet addiction and psychological wellbeing among youth of Kashmir. Results revealed that there is significant negative correlation between internet addiction and psychological wellbeing as correlation coefficient $\left(\mathrm{r}=-.218^{*}, \mathrm{P}=.030\right)$ is significant at 0.05 level of significance. In light of above empirical evidence the hypothesis no. $\mathrm{H}_{01}$ which states "There will be no significant correlation between internet addiction and psychological wellbeing among youth of Kashmir” stands rejected 
Table 2 Showing comparison of mean scores of both internet addiction and psychological well-being among youth of Kashmir with respect to their gender.

\begin{tabular}{|c|c|c|c|c|}
\hline Variable & $\mathbf{N}$ & df & Mean & t-value \\
\hline & Male $=50$ & & 50.16 & \\
\hline Internet addiction & & 98 & & $3.626 *(\mathrm{p}<.001)$ \\
\hline & Female $=50$ & & 40.46 & \\
\hline & Male $=50$ & & 84.2600 & \\
\hline Psychological well-being & & 98 & & $0.841^{\mathrm{NS}}(\mathrm{p}=.43)$ \\
\hline & Female $=50$ & & 82.3400 & \\
\hline
\end{tabular}

*Significant at 0.05 level of significance; NS = Not Significant.

Table 2 presents an overview of the t-value of both internet addiction and psychological wellbeing among youth of Kashmir with respect to their gender. As depicted by the table, Internet addiction among youth of Kashmir, with respect to their gender, differ significantly as the t-value 3.626* ( $<$.001) is significant at 0.05 level of significance, while psychological well-being among youth of Kashmir, with respect to gender, did not differ significantly as the tvalue $0.841^{\mathrm{NS}}(\mathrm{p}=.43$ ) is insignificant at 0.05 level of significance. It is evident from the table that males were high on internet addiction than their counter parts. In the light of above empirical evidence the hypothesis no. $\mathrm{H}_{02}$ stands rejected and hypothesis no. $\mathrm{H}_{04}$ stands accepted.

Table 3 Showing comparison of mean scores of both internet addiction and psychological well-being among youth of Kashmir with respect to their residential status.

\begin{tabular}{llccl}
\hline Variable & N & df & Mean & t-value \\
Internet addiction & Rural=50 & & 43.96 & \\
& Urban=50 & 98 & & $-.952^{\mathrm{NS}}(\mathrm{p}=.343)$ \\
& Rural=50 & & 86.66 & \\
Psychological well-being & & 98 & & $2.48^{*}(\mathrm{p}=.015)$ \\
& Urban=50 & & 86.06 & \\
\hline
\end{tabular}

*Significant at 0.05 level of significance; NS = Not Significant

Table 3 presents an overview of the t-value of both internet addiction and psychological wellbeing among youth of Kashmir with respect to their residential status. As depicted by the table, Internet addiction among youth of Kashmir, with respect to their residential status, did not differ significantly as the t-value $-.952^{\mathrm{NS}}(\mathrm{p}=.343)$ is insignificant at 0.05 level of significance while psychological well-being among youth of Kashmir, with respect to residential status, differ significantly as the $\mathrm{t}-$ value is significant $2.48^{*}(\mathrm{p}=.015)$ at 0.05 level of significance, urban youth were found to be high on the levels of psychological well being as compared to rural 
youth. In the light of above empirical evidence the hypothesis no. $\mathrm{H}_{03}$ stands accepted and hypothesis no. $\mathrm{H}_{05}$ stands rejected.

\section{DISCUSSION AND CONCLUSION}

The present study examines the internet addiction and psychological wellbeing among youth of Kashmir.

- Findings revealed that there is significant negative correlation between internet addiction and psychological wellbeing among youth of Kashmir. This finding is consistent with previous studies that examined psychological wellbeing and internet addiction. For example, Cardak (2013) found that students with higher levels of Internet addiction are more likely to be low in psychological well-being and Waldo (2014) also found significant relationship between internet addiction and psychological well-being.

- Results also revealed that there is a significant difference in internet addiction among youth of Kashmir and insignificant difference in psychological wellbeing among them as far as their gender is concerned. It was found that males are high in internet addiction as compared to their counterparts. The first part of this finding is not consistent with other studies done by Xu, Zhang \& Liu (2011), Waldo (2014), Kawa \& Shafi (2015) in which it was found that there is no significant difference in internet addiction as far as gender of youth is concerned. The second part of this finding is consistent with the previous literature (Winefield, Gill, Taylor \& Pilkington, 2012); Sharma, 2014) which also shows insignificant difference in psychological wellbeing between male and female youth.

- Results also revealed that there is no significant difference in internet addiction among youth of Kashmir as far as their residential status is concerned. The result is not consistent with the study conducted by Kawa and Shafi (2015) which shows a significant difference in internet addiction among rural and urban youth. As far as psychological well-being is concerned results showed a significant difference between rural and urban youth of Kashmir. Urban youth were found to be high on the levels psychological well- being as compared to rural youth of Kashmir. This finding is not consistent with other studies done by Khan, Gangadhara , Lakshm \& Gangadhara (2010) which shows insignificant difference in psychological well-being as far as residential status of youth is concerned.

\section{REFERENCES}

Akin, A. \& Iskender, M. (2011). Internet addiction and depression, anxiety and stress. International online journal of educational sciences, 3(1), 138-148.

Cardak, M. (2013). Psychological wellbeing and addiction among university students. The Turkish journal of journal of educational technology, 12(3), 134-141.

Huppert, F. A., Baylis, N., \& Keverne, B. (2005). The Science of well- being. Oxford, UK: Oxford university press.

Isman, A., \& Dabaj, F. (2004). Attitude of students towards internet. Turkish online journal of distance education, 5(4). 
Kawa, M. H., \& Shafi, H. (2015). Evaluation of internet addiction and psychological distress among university students. Specialty journal of psychology and management, 1(0), 17-23.

Khan, M. A., Gangadhara, G., Lakshmi, S., \& Gangadhara, S. (2010). Determinants Affecting Psychological Well-being of Urban and Rural Adolescents- A Comparative Study. Asian student medical journal, 1(1).

Koc, M. (2011). Internet addiction and psychopathology. The online journal of educational technology, 10(1), 143-148.

Pandiya, M, M., \& Korat, N. R. (2015). Internet addiction and psychological wellbeing among youth of Rajkot district. The international journal of Indian psychology, 2(2), 5-9.

Ryan, R. M., Huta, V., \& Deci, E. L. (2008). Living Well: A Self- determination theory perspective on eudemonia. Journal of happiness studies, 9, 139-170.

Ryff, C. D. \& Keyes, C. (1995). The Structure of Psychological Well-Being. Journal of Personality and Social Psychology, 69(4), 719-727.

Sari, S. V. \& Aydin, B. (2011). Internet addiction among adolescents: the role of self esteem. Procedia- Social \& Behavioral science, 15, 3500-3505.

Sharma, G. (2014). Effect of demographic variables on psychological well being and quality of life. International journal of social science and humanistic research, 2(3), 290- 298.

Waldo, A. (2014). Correlates of internet addiction among adolescents. Psychology, 5(18), 19992008.

Winefield, H. R., Gilli, T. K., Taylor, A.W., \& Pilkington, R. M. (2012). Psychological wellbeing and psychological distress: Is it necessary to measure both? Psychology of wellbeing, 2.

Yang, S., and Tung, C. (2007). Comparison of Internet addicts and non-addicts in Taiwanese high school. Computers in Human Behavior, 23(1), 79-96.

Yapici, I. \& Akbayin, H. (2012). High school students on bended learning. Turkish online journal of distance education, 13(8), 125-129.

Young, K. S. (1998). Internet addiction: The emergence of new clinical disorder. Cyber psychology and behavior, 1(3), 237-244. 